\title{
CONTROLE JUDICIAL DAS POLÍTICAS PÚBLICAS AMBIENTAIS. UMA ANÁLISE JURISPRUDENCIAL CONTEMPORÂNEA
}

\author{
Cecilia Lettninn Torres ${ }^{1}$ \\ Liane Francisca Huning Pazinato ${ }^{2}$
}

\section{RESUMO}

O meio ambiente carece de atenção redobrada consubstanciada no viés constitucional da preservação ambiental para presente e futuras gerações. Nesta ótica, o objetivo deste artigo propiciou a análise do controle judicial na intervenção dos atos do poder executivo, compelindo-o à implementação de políticas públicas ambientais. A partir deste estudo, propôs ao leitor compreender, de que forma o poder judiciário colabora, dentro dos limites da lei, no estímulo da preservação ambiental. Através da análise bibliográfica e da jurisprudência correlata, perfez o entendimento do contexto atual e como essa prática "atípica" tem sido efetivada.

Palavras-chave: Políticas Públicas. Meio Ambiente. Jurisprudência. Poder Judiciário. Controle.

\section{JUDICIAL CONTROL OF ENVIRONMENTAL PUBLIC POLICIES. A CONTEMPORARY JURISPRUDENTIAL ANALYSIS}

\begin{abstract}
The environment needs redoubled attention embodied in the constitutional bias of environmental preservation for present and future generations. In this perspective, the objective of this article allowed the analysis of judicial control in the intervention of the acts of the executive power, compelling it to the implementation of environmental public policies. From this study, he proposed to the reader to understand, in what way the judiciary collaborates, within the limits of the law, in stimulating environmental preservation. Through bibliographic analysis and related jurisprudence, the understanding of the current context and how this "atypical" practice has been carried out is perfect.
\end{abstract}

Keywords: Public Policy. Environment. Jurisprudence. Judicial Power. Control

\section{INTRODUÇÃO}

Em razão da constante estagnação do poder público em promover o mínimo dos direitos sociais e fundamentais à sua população, resta demonstrada a dificuldade do Estado

\footnotetext{
1 Especialista em Direito Ambiental (2017) pela Universidade Federal de Pelotas-RS (UFPEL). Mestranda em Direito e Justiça Social pela Universidade Federal do Rio Grande (FURG). Advogada. Endereço postal: Cel. Augusto de Carvalho 968-Pelotas-RS CEP:96060-150. Endereço Eletrônico cecilettninn @ gmail.com

${ }^{2}$ Doutora em Direito pela Pontifícia Universidade Católica do Rio Grande do Sul (PUC-RS), professora nos cursos de graduação e mestrado da Universidade Federal do Rio Grande (FURG). Endereço postal: Campus Carreiros: Av. Itália km 8 Bairro Carreiros-Rio Grande-RS. E-mail: lianehuning@ gmail.com
} 
em caminhar para um Estado de bem-estar social. A crise do atual sistema estatal no Brasil não demonstra grandes avanços de ordem social. A desídia dos governantes políticos relacionada ao bem-estar social é nítida, e o poder público não consegue ou não pretende contornar essa informação, frente as necessidades do sistema econômico e capitalista.

O bem-estar social está intimamente ligado a questão socioambiental na medida que, garante a existência de direitos mínimos a população, com consequente qualidade de vida, que há muito foi deixada de lado pelos governantes políticos.

O Estado deixou de cumprir o seu compromisso constitucional social com seus cidadãos, em razão disso, surgem necessidades e meios do Ente agir como forma de efetivar a contraprestação com o povo.

Neste contexto, é que o presente trabalho visa como objetivo principal, articular a análise do controle judicial de políticas públicas ambientais no Brasil, bem como, quanto ao compelimento à implementação das políticas e, na busca da efetividade e fiscalização destas. O tema possui grande relevância na atualidade, tendo em vista, certa inércia dos poderes executivo e legislativo, em utilizar dos mecanismos estatais necessários para a prática da preservação socioambiental dentro da sua função típica constitucional, com base nesta justificativa e dada a relevância social, a pesquisa pretende através de estudos jurisprudenciais apresentar os resultados necessários para contribuição socioambiental.

O estudo se baseará na premissa de uma Constituição garantista de direitos, a qual demonstra que o Estado necessita da implementação de instrumentos de aplicabilidade, que possam concretizar o retorno social almejado, principalmente quantos aos direitos fundamentais violados. Justificando, neste panorama, a aplicabilidade das políticas públicas.

Nesta ótica, demonstrar-se-á ainda que, embora existam políticas públicas ambientais instituídas, muitas não são efetivas e tampouco eficazes, já que, carecem de melhores implementações segundo a ótica socioambiental.

Desta forma, visando acrescentar à preservação ambiental um ato eficaz, em meio a omissão Estatal, pode-se contar em situação de excepcionalidade, em razão de matéria constitucional, qual seja, o direito fundamental; com o controle judicial do poder judiciário.

Resta analisar para tanto, se este "controle judicial” não será mais uma forma de conturbar o sistema judiciário, já que nesta seara se dará como análise atípica de suas atribuições, ou uma maneira mais célere de se efetivar os direitos fundamentais à mercê dos atos de gestão governamental.

Neste ínterim será demonstrado, portanto, como se dará esse compelimento, do poder 
judiciário "exigir" do poder executivo e/ou do legislativo, a validade e eficácia dos atos de gestão atinentes a políticas públicas, e quais os limites que devem ser considerados nesta excepcionalidade.

O desenvolvimento do texto delimitou-se a tratar do assunto de políticas públicas ambientais de uma maneira geral, propiciando estabelecer uma conexão da implementação com a consequente efetividade, a fim de que, o leitor perceba o nexo e a costura com os objetivos propostos. A análise jurisprudencial corroborou para essa finalidade.

$\mathrm{Na}$ primeira parte abordar-se-á políticas públicas, conceituando e delimitando o entendimento, para que se tenha noção ampla deste instrumento de prática do agir do Estado.

Num segundo momento, a origem, histórico das políticas públicas ambientais no Brasil, as dificuldades encontradas e as possíveis soluções.

Derradeiramente, tratar-se-á da judicialização da implementação das políticas públicas, por fim, embasada com análise jurisprudencial, com intuito de contextualizar o porquê da intervenção do poder judiciário nas atribuições em tese, do poder executivo, impondo-se os limites e diretrizes pertinentes.

O método de pesquisa utiliza-se de estudos bibliográficos e decisões jurisprudenciais correlatas sobre o tema.

\section{MEIO AMBIENTE E A NECESSIDADE DAS POLÍTICAS PÚbLICAS AMBIENTAIS}

Quando o assunto a ser tratado refere-se ao meio ambiente, predominantemente existe a ideia da visão romanticista, que relaciona o todo ambiental, apenas, com a natureza. Ocorre que, falar em meio ambiente, aduz diferentes necessidades, além é claro, das relacionadas à fauna, a flora e a poluição. O que pretende-se demonstrar é que, para além deste entendimento a projeção que se quer, é de uma visão macro, que deva relacionar com a seguinte conclusão: o caráter socioambiental.

Quando se chega a esta perspectiva, de como esse meio ambiente tem se relacionado diretamente com o ser humano, e o quanto a sua degradação afeta várias vidas-tanto na questão de saúde, ambiente e modos de vida; quanto na questão biológica: com a extinção de diversas espécies de nossa biodiversidade que fazem parte do ciclo biológico da vida, estamos pensando em Direito Ambiental.

É um ciclo, onde todos estão interligados, cada ser, mesmo que microscopicamente, torna-se necessário em todo ecossistema, não podendo ser aceita a conformidade da sua 
extinção.

A partir do cenário alarmante de extinção de espécies, através da poluição excessiva e de outras tantas vertentes que causam o dano ambiental no contexto atual, são determinantes para que população e Estado, somados ao que preceitua o artigo $225 \mathrm{CF} / 1988$, tenham a consciência ecológica, a fim de determinar com seus mecanismos de atuação na defesa ambiental para a presente e futuras gerações, seja com educação ambiental social, seja com os instrumentos de ação a disposição do Estado.

O meio ambiente ainda carece de múltiplas defesas por parte do Estado, as legislações são múltiplas, mas suas efetividades preocupam cada dia o atual cenário. Nesta lógica, é fundamental um repensar, e um novo rigor das implementações e formulação de legislação, nesta área, e um incentivo na participação popular e nas defesas ambientais para que possa ser minimizados os atos ineficientes que geram o descumprimento Estatal.

Segundo Beck (2013) vivemos em uma sociedade de risco, onde o ser humano está exposto ao risco por pura e simples falta de cumprimento principalmente por parte do Estado pela deveras omissão de análise dos princípios básicos de direito ambiental: precaução e prevenção.

Aliados ao entendimento de Beck, concomitantemente com a negligência e omissão estatal, observa-se ainda, que a sociedade também tem se mostrado, omissa e estagnada ao seu dever constitucional ambiental.

Neste sentindo, para que haja efetividade no cumprimento das normas e de todas as diretrizes ambientais, intui primeiramente cumprir com o que compreende o princípio da prevenção, princípio ambiental no qual se conhece o risco, bem como, as suas consequências.

Por outro lado, quando se trata de efetivar o princípio da prevenção, a dificuldade é outra, principalmente por parte dos agentes envolvidos, eis que trata-se de um risco abstrato onde não se conhece e/ou não se pode calcular as consequências da sua falta de análise.

Exemplo disso, é a difícil aplicabilidade de licenciamento ambiental em diversos Estados e municípios brasileiros, que não contam com rigor coercitivo, no enfoque de liberação de empreendimentos de grandes e renomados investimentos, visando por vezes, a necessidade de mercados e a complementação de um sistema cíclico, como o capitalismo. Neste sentindo ainda, dentro da lógica do Licenciamento Ambiental, relevante destacar a falta de transparência e burocratização do mecanismo. O licenciamento ambiental ${ }^{3}$ é um

3 O licenciamento ambiental é uma exigência legal a que estão sujeitos todos os empreendimentos ou atividades que empregam recursos naturais ou que possam causar algum tipo de poluição ou degradação ao meio ambiente. É um procedimento administrativo pelo qual é autorizada a localização, instalação, ampliação e operação destes 


\title{
CONTROLE JUDICIAL DAS POLÍTICAS PÚBLICAS AMBIENTAIS. UMA ANÁLISE \\ JURISPRUDENCIAL CONTEMPORÂNEA
}

mecanismo previsto na constituição e na legislação brasileira e sua aplicabilidade é motivo de muitas discussões, em razão da falta de bom senso e ponderação entre as partes. Mesmo sendo um instrumento para assegurar a qualidade de vida das pessoas para o futuro, na prática o assunto é outro.

Visto isso, dentre os diversos instrumentos propostos, nas atuações legislativas, executivas e judiciárias, a que merece destaque é a formulação de políticas públicas, que é uma das atribuições do poder executivo e legislativo.

Considera-se que as Políticas públicas são ferramentas a favor do Estado para executar uma ação positiva em prol da promoção de justiça social, na busca da efetiva concessão de direitos fundamentais.

A política pública se apresenta como objeto e ramo de conhecimento: o objeto de conhecimento (fenômeno) possui variadas definições. Em artigo, Celina Souza[1] traz as definições de Lynn (1980): "conjunto de ações de governo que irão produzir objetivos específicos", de Peters (1986): "política pública é a soma das atividades dos governos, que agem diretamente ou através de delegação, e que influenciam a vida dos cidadãos" e de Dye (1984): "o que o governo escolhe fazer ou não fazer".(EMERIQUE, 2012)

Ao que tudo indica, um dos fundamentos Constitucionais das políticas públicas é a redução das desigualdades e a promoção do desenvolvimento.

\begin{abstract}
Ora, de acordo com o modelo de Estado Social, adotado na Constituição de 1988,a ação do Estado deve estar voltada à redução das desigualdades sociais, econômicas, regionais, entre grupos, ou, em última análise, à produção de justiça social. De fato, as Constituições do Estado Social, diferentemente do que ocorre no Estado Liberal, trazem uma série de novas tarefas e exigências para a atuação dos Poderes Públicos, que devem se organizar para cumprir os fins e objetivos coletivos nela previstos. (DUARTE, 2015, pág.14).
\end{abstract}

Partindo desta premissa, ao se implementar ou projetar uma política pública, o responsável, seja o Estado, ou outro agente envolvido, deve considerar qual objetivo da sua elaboração e implementação, além do resultado que pretende obter para a satisfação e

empreendimentos e/ou atividades. A responsabilidade pela concessão fica a cargo dos órgãos ambientais estaduais e, a depender do caso, também do Instituto Brasileiro do Meio Ambiente e dos Recursos Naturais Renováveis (Ibama), quando se tratar de grandes projetos, com o potencial de afetar mais de um estado, como é o caso dos empreendimentos de geração de energia, e nas atividades do setor de petróleo e gás na plataforma continental.As bases legais do licenciamento ambiental estão traçadas, principalmente, na Lei 6.938/81, que dispõe sobre a Política Nacional do Meio Ambiente e traz um conjunto de normas para a preservação ambiental; nas Resoluções do Conselho Nacional do Meio Ambiente (Conama) 001/86 e 237/97, que estabelecem procedimentos para o licenciamento ambiental; e na Lei Complementar 140/11, que fixa normas de cooperação entre as três esferas da administração (federal, estadual e municipal) na defesa do meio ambiente.http://www.oeco.org.br/dicionario-ambiental/27321-o-que-e-licenciamento-ambiental/. 
benefício social. Essa consideração em regra, pode ser realizada através de uma das fases da política pública após a sua implementação: avaliação da política pública.

O Comitê de Assistência ao Desenvolvimento da OCDE assinala que o propósito da avaliação é determinar a pertinência e alcance dos objetivos, a eficiência, efetividade, impacto e sustentabilidade do desenvolvimento. A avaliação deve proporcionar informação que seja crível e útil para permitir a incorporação da experiência adquirida no processo de tomada de decisão. A avaliação deve ser vista como um mecanismo de melhoria no processo de tomada de decisão, a fim de garantir melhores informações, sobre as quais eles possam fundamentar suas decisões e melhor prestar contas sobre as políticas públicas (TREVISAN, 2008, p.536).

Ademais, cumpre informar que dentro da conceituação de Política Pública necessário compreender ainda, outras perspectivas existentes:

O tipo de política pública - quatro tipos: distributivas (caracterizadas por um menor
grau de conflito em sua formulação), redistributivas (grande grau de conflito, impõe
perdas e ganhos), regulatórias (os graus de conflito são variáveis) e constitutivas
(mudam as regras e estruturas, a polity);- O ciclo da política pública apresenta
modelo de análise que decompõe a política pública em fases: formulação, aplicação
e controle de impactos. Klaus Frey propõe a seguinte divisão, a saber: percepção e
definição de problemas, agenda-settin., elaboração de programas e decisão,
implementação de políticas e, finalmente, a avaliação de políticas e a eventual
correção da ação. Tal modelo enfoca a pergunta: Como o problema entra na agenda
pública? Numa aproximação com o direito poderíamos perguntar: Como interagem
agenda política e Constituiçãa? Em quais etapas podem ocorrer controle
jurisdicional?(EMERIQUE, 2012).

A formulação de uma política pública, bem como, sua análise, devem ser detalhadamente esmiuçadas para conclusão de todo o aparato estatal, ocorre que este trabalho não tratará especificamente de esgotar este entendimento

Apenas, a título de conhecimento, para demonstrar que o campo de análise das políticas públicas é amplo e demasiadamente técnico.

Todas essas definições de política pública articulam a ação de governo à realização dos mandamentos constitucionais e à plena efetivação dos direitos fundamentais. Tal entendimento constrange o poder discricionário das variáveis de formulação da agenda política, obrigando os agentes públicos, grupos de interesse e demais atores envolvidos a terem como fator limitador de suas disputas a Constituição. Esta é, em si, fruto de disputa política e da correlação de forças e grupos de interesses presentes em 1988 e, a priori, seu papel está na limitação do poder do Estado e suas ações políticas públicas. A crítica que pode ser feita é a de que, não necessariamente, uma política pública se propõe a dar efetividade aos direitos fundamentais. Ela pode ser meramente simbólica, sem qualquer eficácia para solucionar o problema ao qual se propôs resolver, tendo em vista apenas dar satisfação à sociedade.(EMERIQUE, 2012) 
Neste sentido, exige-se do Estado, através de ato do poder executivo ou legislativo que utilize de políticas públicas, proporcionando a promoção dos direitos fundamentais, com o fornecimento, de moradia para todos, tratamento sanitário eficiente, entre outros direitos sociais mínimos de dignidade humana.

Para entender melhor o instituto das políticas públicas ambientais, e sua efetividade deve ser proposto o estudo de alguns detalhes e considerações importantes do histórico da política pública ambiental no Brasil.

\title{
1.1 HISTÓRICO DAS POLÍTICAS PÚBLICAS AMBIENTAIS NO BRASIL
}

No Brasil, a origem das políticas públicas ambientais, não representa ser um exemplo. Pelo contrário, as políticas públicas ambientais são esquecidas e ineficazes.

Embora exista uma legislação que determine normativamente a realização delas, como a Política Nacional do meio Ambiente, não é o suficiente e tampouco eficaz, em razão da difícil aplicabilidade, da burocracia e falta de transparência nas suas implementações.

\begin{abstract}
No que tange às políticas públicas de cunho ambiental em nosso país, cabe ainda lembrar que, historicamente, o Brasil sempre foi marcado por uma economia predominantemente exploratória de seus abundantes recursos e riquezas naturais, pautando todo seu desenvolvimento (econômico, político, social, etc.) na exaustiva produção de produtos primários (agricultura, pecuária, extração de metais preciosos, extração de madeira e outros) de modo agressivo e predatório.[...]. Não obstante, há de se mencionar que, desde as primeiras décadas do século XX, o país já vinha promulgando leis esparsas como os já citados Código Florestal, Código de Águas, de Minas, entre outros; mas, sem exceção, todos relegados, na prática, a segundo plano de importância, um claro sinal de que o Poder Público sempre priorizou o capital e a economia em detrimento da proteção ambiental. Em face da ação dos movimentos conservacionistas internacionais $\mathrm{e}$ as pressões externas pela preservação do patrimônio natural e pela melhor qualidade de vida, surgida principalmente entre as décadas de 1970 e 1980, o país passou a adotar políticas ambientais de proteção e conservação, utilizando-se de diversos mecanismos legais, para tanto pautando suas diretrizes, inclusive, no já mencionado princípio de “desenvolvimento sustentável".(SALHEB, 2009)
\end{abstract}

Ademais, o marco introdutório da organização e implementação das políticas públicas ambientais no Brasil foi através da promulgação da Lei 6.938/1981, que instituiu a Política Nacional do Meio Ambienta (PNMA), que a partir das suas diretrizes, passaram a guiar a Política Nacional Ambiental, observando as de caráter econômico, social e cultural (Salheb, 2009).

A política nacional do meio ambiente tem por objetivo a harmonização do meio 
ambiente com o desenvolvimento socioeconômico (desenvolvimento sustentável). Essa harmonização consiste na conciliação da proteção ao meio ambiente, de um lado, e a garantia de desenvolvimento socioeconômico, de outro, visando assegurar condições necessárias ao progresso industrial, aos interesses da segurança nacional e à proteção da dignidade da vida humana(Art. $2^{\circ}$ da Lei n. 6.938/81).

Com base no contexto histórico, diversas foram as tentativas de implementar-se alguma política ambiental que trouxessem a efetiva tutela. Em uma de suas tentativas, sem êxito pelo Estado, por falta do acompanhamento devido tida como uma política esquecida, fora o programa "Nossa natureza" em 1988.

Como exemplo de políticas públicas ambientais lastreadas pela PNMA pode-se citar o programa "Nossa Natureza", de 1988, que propunha uma estratégia de reformulação da legislação ambiental e instituía diretrizes para promover a proteção do meio ambiente. Inicialmente a ideia era muito boa, mas falhou na sua implementação e acabou esquecida no arcabouço jurídico nacional dentre tantas outras que a antecederam, dadas as sucessivas crises econômicas da economia nacional naquele período e a constante pressão do capital internacional. Ao se falar de políticas públicas ambientais, deve-se ter em mente que estas, sob pena de ineficácia, "não podem ser desconexas ou descoordenadas". Deve haver, então, complementaridade entre as ações e objetivos, caso contrário perder-se-ão no vazio da inépcia posto que a própria vida, em todas as suas formas, é a destinatária destas ações e objetivos. (SALHEB, 2009, p. 14-15)

Como forma de dar vazão as ações e objetivos das políticas públicas propostas, a criação do IBAMA teve o condão de abrir caminho para a fiscalização das políticas voltadas ao meio ambiente. Neste sentido, os grandes problemas que encontram-se nos dias de hoje são: a falta de coordenação e gestão das atribuições deste instituto e organização, para que não se confundam órgãos de fiscalização, de preservação de unidade e pesquisa científica. (ANTUNES, 2008. p.122)

Diversas são as dificuldades de organização no que tange a gestão de governo, principalmente para que sejam concretizados os direitos fundamentais ambientais mínimos para a geração da consequente justiça social.

As políticas públicas necessitam muito além das suas implementações, mas de atores compromissados com o seu acompanhamento.

Através da falta de credibilidade, da efetividade de políticas públicas ambientais brasileiras com a consequente má-gestão governamental, é que passou-se a cobrança desta efetividade ao poder judiciário, para que pudesse intervir dentre as funções típicas do poder executivo.

\section{DA JUDICIALIZAÇÃO DA POLÍTICA SOCIOAMBIENTAL}


Em razão da ineficácia e da fragilidade que possui a legislação ambiental no Brasil, aliado ao fato da proteção ambiental estar em segundo plano quanto sua aplicabilidade, em detrimento do desenvolvimento econômico, bem como, a consequente omissão estatal em implementar políticas necessárias, a jurisprudência tem determinado a intervenção do poder judiciário no compelimento da implementação destas políticas.

Neste contexto, a discussão sobre o tema é longa, que deve estar atrelado ao estudo e análise do direito no âmbito do direito constitucional quanto a análise do tema separação dos poderes da união, correlatos ao tratamento do controle judicial das políticas públicas,

Cumpre ressaltar que este trabalho pretende apenas dar ensejo as matérias discutidas em algumas das decisões judiciais que corroborarão com o referencial teórico utilizado, na busca dos resultados a serem concluídos. Não se tratando, portanto, de esgotar a análise do tema proposto.

Em prol desta efetividade, principalmente frente a necessidade de insurgir-se em favor do princípio ambiental da precaução, é que se fala sobre a necessidade de análise e controle por parte do poder judiciário na busca da efetividade e da solução de conflitos entre Estado e meio ambiente.

$\mathrm{Na}$ ótica da separação de poderes constitucionais, as esferas dos poderes administrativos estão direcionando em outros entendimentos, com base no estudo de cada caso, como forma excepcional de competência, e sendo exercidas muitas vezes em seu caráter atípico, como é o caso do controle judicial de políticas públicas.

Para elucidação sobre como o direito constitucional contempla o estudo da separação dos poderes da união, convém resumir o entendimento de que os três poderes são independentes e harmônicos entre si, são eles: Executivo, legislativo e judiciário previstos na

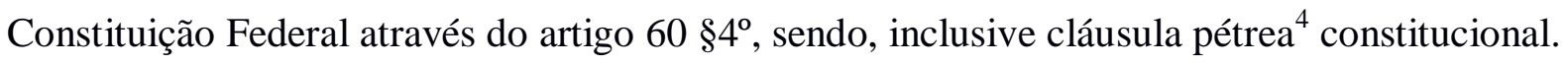

Á cada um destes poderes, devem-se atentar a sua função típica, que em breves palavras, são:

Poder Executivo: o poder que exerce tipicamente a função administrativa. Além disso, pode exercer a função legislativa em alguns casos, como na edição de medidas provisórias, leis delegadas ou decretos. Poder Legislativo: É o poder que se encarrega da função legislativa (normativa).Portanto, cabe ao Poder Legislativo, a função normativa. Entretanto, ele também desempenha a função administrativa quando, por exemplo, realiza licitações, faz concurso público, nomeia os aprovados, etc. Assim como, desempenhar a função jurisdicional quando, por exemplo, o Senado processa e julga o Presidente e o Vice-presidente da República por crimes de responsabilidade. Poder Judiciário: É o poder que desempenha a função jurisdicional

4 aquelas que não são objetos de deliberações/mudanças. 
(função de julgar). Entretanto, cabe ao Poder Judiciário, exercer a função administrativa nos mesmos casos previstos para o Legislativo (concurso, licitações, firmar contratos, nomear pessoal, etc.); e executa a função legislativa quando, por exemplo, os tribunais editam seus regimentos internos.(SALHEB, 2009, p.70-72).

Baseado nesta divisão, resta claro que o poder judiciário não é o responsável pela instituição de políticas públicas, já que não cabe às suas atribuições a administração de um governo. Essa competência se dá estritamente, entre o poder executivo e o legislativo. Seja em forma de implementação das políticas, como atribuição de competência do poder executivo nas formas de gestão, como por exemplo, política de governo- visando a preservação ambiental, ex. Política para redução de resíduos sólidos, seja em forma de legislação, quando o poder legislativo legisla uma política pública em forma de lei, como por exemplo as políticas de Estado que pode ser representada como modelo o Ex. ICMS ecológico existente em vários estados da federação, trata de uma legislação que cria critérios para repartição de receitas de ICMS dentre os municípios, com base nos critérios estipulados nesta legislação, visando a proteção ambiental.

Com base neste cenário, quando se fala em efetividade de política pública deve ser ressaltado que, gestores públicos ao terem uma política instituída, e colocando-a em prática, devem acompanhar o seu desenvolvimento, com a devida avaliação técnica pertinente. De fato, observa-se que na prática isto não ocorre com eficiência, devido a desorganização e inércia da administração pública dentre diversos fatores que acarretam o insucesso da política, agravados por déficit de recursos, e outras variáveis que não ensejam retorno positivo, obrigando a administração pública estar consciente que o Estado libera recursos e comumente não são devidamente utilizados, gerando o insucesso da política com o consequente resultado falho na concretização dos direitos fundamentais sociais,

Nesta lógica, resultados como estes oriundos deste processo ,não responderão as seguintes perguntas básicas que são o núcleo da criação de políticas públicas: quem ganha o que? Por quê? E que diferença faz, já que, não proporcionou o retorno social almejado.

Para que se efetive a justiça social, deve-se repensar as práticas intervencionistas aliadas para concretização de alguns direitos fundamentais sociais.

Neste ínterim, já se sabe que políticas públicas são voltadas para a tutela socioambiental e por isso precisam ser institucionalizadas na promoção dos direitos e deveres nesta abrangência, e para este enfoque, necessário se faz, um planejamento e acompanhamento efetivo para que esta política possa ser eficaz, trazendo o devido retorno para sociedade e meio ambiente. Desta forma, poderá se chegar a uma possível concretização 
do dever do Estado por parte do Direito Socioambiental.

A causa, portanto, de uma política pública ser ineficaz ou inefetiva, necessita da análise do poder judiciário, para que possa delimitar ou concretizar o direito exposto. Esta análise observa ainda, que a falta de conhecimento por parte dos gestores, ou atores envolvidos na efetivação de uma política já instituída, é, ainda, aliado a outros fatores, o que ocasionam a necessidade da intervenção judicial por ato falho governamental, demonstrando, portanto, a não ocorrência do devido controle e acompanhamento da implementação.

Aliados a falta de eficácia e gestão das políticas públicas por parte dos poderes executivos e legislativo, sobrevêm analisar mesmo que brevemente, o papel da sociedade na exigência de seus direitos:

É impossível chegar a um entendimento do que sejam as políticas públicas ambientais se deixar de considerar o jogo de poder e de interesses, ou melhor dizendo, da correlação de forças entre os diversos atores sociais que influenciam na elaboração e implementação de tais políticas. Enxergar as políticas públicas ambientais tão somente como resultado da ação estatal, desconsiderando os diversos atores sociais (globais, nacionais e locais), os poderes e as negociações a partir de onde se originam as políticas públicas ambientais consiste em erro que leva a uma compreensão apenas parcial e superficial do que se possa entender como política pública ambiental. Decerto: Parece impossível debruçar-se sobre o tema das conquistas na área ambiental apenas do ponto de vista do Estado, sem considerar o papel da sociedade civil. Qualquer tentativa neste sentido não daria conta da complexidade do tema, já que a problemática ambiental envolve um vasto campo de conflitos, mobilizando diferentes sujeitos sociais em espaços sociais também diferenciados (SILVA, 2010, p.75).

A sociedade civil, tem um papel importante nos resultados referentes a ineficácia da política pública e deve, aliado a este ideal ativista, assegurar este espaço agindo ativamente por meio de movimentações sociais que repercutam na pressão social ao poder público concluir com eficácia o seu papel.

Concluídas as análises e considerações a respeito da possibilidade e necessidade do controle judicial, com convicção de que é recorrente a judicialização da política ambiental , convém analisar na prática, quais as causas mais apuradas, a natureza das reclamações, e o teor constitucional permissivo dessa interferência de poderes, através da análise jurisprudencial a seguir.

\subsection{ANÁLISE JURISPRUDENCIAL CORRELATA}

Através da análise das decisões judiciais é que se pode verificar na prática, como o 
judiciário tem enfrentado e se posicionado frente a interferência na sua atribuição e comando da implementação das políticas públicas.

Necessário, portanto, que sejam analisadas algumas jurisprudências que abordam as diretrizes judiciárias em matéria que envolve a política socioambiental:

DIREITO ADMINISTRATIVO, AMBIENTAL E PROCESSO CIVIL. APELAÇÃO. AÇÃO CIVIL PÚBLICA. “LIXÃO”. IMPLANTAÇÃO DE POLÍTICAS PÚBLICAS AMBIENTAIS. POSSIBILIDADE. SEPARAÇÃO DE PODERES. VIOLAÇÃO. INOCORRÊNCIA. ASTREINTES. 1. A sentença condenou o Município de São Mateus-ES a abster-se de depositar lixo em área do bairro Liberdade, "qualquer que seja o custo da operação", passando a despejar os resíduos urbanos em área do bairro Litorâneo, até a implantação do projeto "Espírito Santo sem lixão" ou programa equivalente, fixando multa única de $\mathrm{R} \$ 600 \mathrm{mil}$, por descumprimento. 2. O Ibama constatou as infrações ambientais, com a poluição em área de manguezal, a partir de depósito irregular de lixo, diariamente revirado por " catadores", em meio a urubus e animais. Ao lado do "Lixão de São Mateus" funciona creche, estando as crianças sujeitas aos seus efeitos nocivos, e mesmo após o TAC com o Iema, e o Auto de Infração e Termo de Apreensão do Ibama, o lixo continuou sendo despejado na área embargada. 3. Incumbe ao Judiciário compelir a administração a implementar políticas públicas de meio ambiente, para recuperar a área degradada, sem ofensa à separação dos Poderes. Deve o Município abster-se de lançar os resíduos sólidos no bairro urbano, recuperando a área degradada, sem prejuízo da discricionariedade para escolher o local mais adequado consoante a sua disponibilidade orçamentária. Precedentes do STJ e do STF. 4. O direito fundamental ao meio ambiente equilibrado, deve ser protegido pelo Poder Público e defendido pela coletividade, estando o agente poluidor obrigado, independente de culpa, a reparar os danos causados por sua atividade. Aplicação da Constituição, art. 225 e Lei n ${ }^{\circ}$ 6.938/1981, arts. $3^{\circ}$, IV e 14, $\S 1^{\circ}$. Precedentes. 5. (...). 8. Apelação parcialmente provida.(TRF-2 - AC: 200650030001363 RJ, Relator: Desembargadora Federal NIZETE LOBATO CARMO, Data de Julgamento: 20/10/2014, SEXTA TURMA ESPECIALIZADA, Data de Publicação: 03/11/2014)

ADMINISTRATIVO E CONSTITUCIONAL. POLÍTICAS PÚBLICAS AMBIENTAIS E DE SAÚdE. TRATAMENTO DE ESGOTO. OMISSÃO. Demonstrada a existência de omissão injustificada dos poderes públicos na implementação das políticas públicas para assegurar a higidez ambiental e a saúde da população, impõe-se a condenação na obrigação de fazer consistente na implantação de sistema de tratamento de esgoto adequado.(TRF-4 - AC: 17675 SC 2004.72.00.017675-8, Relator: MARGA INGE BARTH TESSLER, Data de Julgamento: 26/08/2009, QUARTA TURMA).

Nas duas decisões os julgadores não se abstiveram de compelir o poder público na implementação da política pública para objetivo social analisado, de maneira que não entenderam, os julgadores, ser a competência das diferentes atribuições ofensa ao princípio da separação de poderes, deixando claro que, em tratando-se de matéria ambiental, ou seja, direito fundamental, a necessidade de que sejam efetivados tais direitos deve ser maior do que a violação ao princípio da separação de poderes.

O entendimento do Supremo Tribunal Federal através de sua ministra Carmem Lúcia 
em casos correlatos, é favorável as intervenções excepcionais dos poderes dentro dos limites da lei, em se tratando de direitos previstos constitucionalmente:

"(...) o Poder Judiciário, em situaçães excepcionais, pode determinar que a
Administração Pública adote medidas assecuratórias de direitos constitucionalmente
reconhecidos como essenciais, sem que isso configure contrariedade ao princípio da
separação dos Poderes", ressaltando, ainda, que "a análise da excepcionalidade da
situação em concreto, a ensejar a intervenção, ou não, do Poder Judiciário na
implementação de políticas públicas cabe ao Tribunal a quo, e não ao Supremo
Tribunal Federal." (EDRE n. 700.227/SC, Relatora Ministra Cármen Lúcia j.
23.4.2013).

Na jurisprudência abaixo, o poder judiciário julgou análise de um plano de controle de poluição veicular que já estava previsto como parte integrante da Politica Nacional do Meio ambiente e até o presente momento o poder executivo não havia promovido esta implementação o que acarretou pelo entendimento do poder judiciário, não existir violação ao princípio da separação de poderes por novamente tratar-se de direito essencial (meio ambiente).

EMENTA: ação civil pública. Elaboração de Plano de Controle de Poluição Veicular e implementação do Programa de Inspeção e Manutenção Veicular. Possibilidade. Inércia e morosidade da Administração. Violação do princípio da separação dos poderes. Não ocorrência. Ação civil pública proposta pelo Ministério Público Federal a fim de determinar a elaboração de Plano de Controle de Poluição Veicular -- PCPV no Estado de Santa Catarina e implementação do Programa de Inspeção e Manutenção Veicular. A Lei n. 8.723, de 28 de outubro de 1993, dispõe sobre a redução de emissão de poluentes por veículos automotores, como parte integrante da Política Nacional de Meio Ambiente, bem como procedimentos de controle da poluição. As Resoluções 418/2009, 426/2010 e 435/2011 do CONAMA estabelecem critérios para a elaboração de Planos de Controle de Poluição Veicular PCPV, para a implantação de Programas de Inspeção e Manutenção de Veículos em Uso - I/M pelos órgãos estaduais e municipais de meio ambiente. O Poder Judiciário, em situações excepcionais, pode determinar que a Administração Pública adote medidas assecuratórias de direitos constitucionalmente reconhecidos como essenciais (meio ambiente), sem que com isso configure violação do princípio da Separação de Poderes. (TRF4, AC 502953140.2014.4.04.7200, TERCEIRA TURMA, Relatora VÂNIA HACK DE ALMEIDA, juntado aos autos em 27/02/2018)

CONSTITUCIONAL E AMBIENTAL. AÇÃO CIVIL PÚBLICA. DEGRADAÇÃO DO RIO PIRANHAS-AÇU. DESPEJO DE ESGOTOS NÃO TRATADOS. ACORDO JUDICIAL, COM VISTAS A IMPLANTAÇÃO PROGRESSIVA DE UM SISTEMA DE ESGOTAMENTO SANITÁRIO QUE COMPREENDA A COLETA E O TRATAMENTO DE EFLUENTES, ENTRE OUTRAS OBRIGAÇÕES. MEDIDAS SANEADORAS DAS IRREGULARIDADES AMBIENTAIS. ACORDO HOMOLOGADO POR SENTENÇA. INGERÊNCIA DO PODER JUDICIÁRIO NA DISCRICIONARIEDADE ADMINISTRATIVA. INOCORRÊNCIA. ALEGAČ̃̃O DA CLÁUSULA DA RESERVA DO POSSÍVEL. APELO IMPROVIDO. 1. Ação Civil Pública ajuizada pelo Ministério Público Federal, 
objetivando compelir diversos Municípios, dentre os quais o Apelante, a implantar, progressivamente, um sistema de esgotamento sanitário que compreenda a coleta e o tratamento de efluentes, entre outras obrigações. (..) 2. (...). 3. Sustentou o Município Apelante que o Poder Judiciário está interferindo na discricionariedade administrativa ao estabelecer prazo para a realização de obras requeridas pelo Ministério Público, para as quais, inclusive, não existem recursos, necessitando de prévia dotação orçamentária. 4. (..). 5. (..). 6. Por outro lado, o acordo judicial envolve apenas a estipulação de prazos para a realização de políticas públicas ambientais as quais o ente público já se obrigaria naturalmente a realizar, e não a prestação de valores patrimoniais imediatos. 7. Incabível a alegação de violação à separação dos poderes, tendo em vista que a controvérsia trata de questão ambiental, consistente na degradação do rio Piranhas-Açu, mediante o despejo de esgotos não tratados, questão afeta a garantia constitucional do mínimo existencial, de modo a permitir a exigência de execução de política pública, sem que seja possível a alegação da cláusula da reserva do possível. Entendimento do Supremo Tribunal Federal na ADPF $\mathrm{n}^{\circ}$ 45, Relator Ministro Celso de Mello. 8. Apelação improvida.(TRF-5 - AC: 4973220124058402, Relator: Desembargador Federal Geraldo Apoliano, Data de Julgamento: 08/05/2014, Terceira Turma, Data de Publicação: 14/05/2014)

Nota-se a partir da análise da decisão acima, que o judiciário não se absteve quanto a matéria ambiental, devendo sim ocorrer a interferência, de maneira a compelir o Estado a execução da política, calcados na decisão do Relator Ministro Celso de Mello, quando da decisão da ADPF $n^{\circ} 45$ tratando sobre algumas vertentes dessa interferência entre os poderes, limitando à exceção de valores orçamentários, o qual referenciou como "reserva do possível" informando que não dispunha o ente federado para implementar determinada política, como óbice ao entendimento, deve ser levado em conta a razoabilidade e a ponderação por parte do poder judiciário compelindo ao poder executivo os atos que são de sua atribuição..

O Ministro Celso de Melo, na decisão proferida na ADPF n 45/2004 afirmou, quanto ao tema relativo à reserva do possível, que "a realização dos direitos econômicos, sociais e culturais depende, em grande medida, de um inescapável vínculo financeiro subordinado às possibilidades orçamentárias do Estado, de tal modo que, comprovada, objetivamente, a incapacidade econômico-financeira da pessoa estatal, desta não se poderá razoavelmente exigir, considerada a limitação material referida, a imediata efetivação do comando fundado no texto da Carta Política.

Por outro lado, há julgados em que os entendimentos restam contrários, embora pela análise jurisprudencial denotam-se de matérias específicas, considerando direitos individuais, como por exemplo, nos procedimentos como EIA- Estudo de impacto Ambiental e/ou Licenciamento ambiental, que o judiciário entende violação ao princípio da separação de poderes, quanto ao poder discricionário da administração.

EMENTA: AdMinistrativo. AMBIENTAL. AÇão CIVIL PÚbliCa. LICENCIAMENTO AMBIENTAL. OBRA DE PAVIMENTAÇÃO. ESTUDO 


\section{PRÉVIO DE IMPACTO AMBIENTAL. DESNECESSIDADE.} ALTERNATIVA. 1. O Estudo de Impacto Ambiental (EIA) constitui trabalho técnico elaborado por equipe multidisciplinar que se afigura indispensável para a análise do pedido de Licenciamento Ambiental quando se tratar de empreendimento que pode causar significativo impacto ambiental. 2. As condicionantes específicas, aliadas à exigência do IAP de apresentação de Relatório de Controle Ambiental (RCA/PCA), por ocasião da obtenção da futura Licença de Operação, cumpre a exigência legal e constitucional de realização do Estudo Prévio de Impacto Ambiental; isto porque, nos termos da Resolução no 237 da CONAMA, de 19 de dezembro de 1997 (art. 1 ${ }^{\circ}$, inciso III), o referido Relatório ou Projeto de Controle Ambiental (RCA/PCA) integra as modalidades de Estudos Ambientais exigidos para obtenção de licenciamento ambiental, competindo ao ente ambiental definir uma ou outra espécie de estudo, segundo a atividade ou empreendimento a ser realizado (art. $3^{\circ}$, parágrafo único). 3. O Poder Judiciário não pode, como regra, interferir nas políticas públicas definidas pelos demais Poderes. Não cabe ao Judiciário realizar opções políticas ou eleger alternativas que estejam dentro do poder discricionário da Administração, salvo se drasticamente mal-ferido o princípio da legalidade e da razoabilidade, nos casos de completa falta ou falha do procedimento administrativo empregado. (TRF4, AC 500117058.2010.404.7004, QUARTA TURMA, Relator LUÍS ALBERTO D'AZEVEDO AURVALLE, juntado aos autos em 10/12/2015)

Nesta decisão, o julgador entendeu como interferência na competência do poder Estatal, na forma de realização de opções políticas ou determinando as alternativas para sanar a questão, resumindo em um entendimento que o poder judiciário poderá interferir caso necessário adentrar no mérito de violação ao princípio da legalidade ou razoabilidade. Implica justificar que o entendimento jurisprudencial supra é correlato à interferência do poder judiciário quando a uma decisão discricionária, do poder estatal dentro da análise do instrumento de Licenciamento ambiental e não no compelimento de políticas públicas e análise da efetividade das mesmas.

Dentre as análises jurisprudenciais referente a políticas públicas houveram também decisões quanto a preservação do patrimônio cultural e os deveres e obrigações como direitos fundamentais, e o contraponto surgiu a resposta do Estado contra o princípio da reserva do possível para não instituição de políticas voltadas a conservação do patrimônio em questão, nestes tipos de casos, houve ponderação e razoabilidade considerando a alegação estatal com a observância do princípio arguido.

Conclui-se que a importância no desenvolvimento da política faz toda a diferença na concretização dos direitos. O aparato Estatal deve responder positivamente com um retorno de aplicabilidade para haver a eficácia e concretização na busca de desigualdades e tutelas ambientais.

O ponto primordial que merece destaque ao analisar as decisões judiciais, é que resta comprovado que muitas das políticas públicas além de não são eficazes, não são 
implementadas, sendo necessário o compelimento por parte do poder judiciário para o retorno esperado.

Existe pouca eficácia social do direito fundamental ao meio ambiente equilibrado e do papel do poder judiciário na efetivação do direito ao meio ambiente ecologicamente equilibrado (PAGLIARINI, p. 81)

\begin{abstract}
APELAÇÕES CÍVEIS. REEXAME NECESSÁRIO. DIREITO PÚBLICO. AMBIENTAL. POLUIÇÃO SONORA. CONTROLE JUDICIAL DE POLÍTICAS PÚBLICAS. OMISSÃO DO PODER PÚBLICO NÃO CARACTERIZADA. - (...). - A realização das políticas públicas é encargo do Poder Executivo, de sorte que ao Poder Judiciário é dado intervir, ordenando a execução de políticas, somente se constatada violação a direitos fundamentais, seja por ação ou omissão do ente responsável. A possibilidade de exercício do controle judicial sobre as políticas públicas pressupõe a violação a direitos fundamentais como decorrência de injusta omissão ou ação indevida do Poder Público. Na hipótese dos autos, o Município demonstrou ter atuado... diretamente para o fim dos eventos danosos conforme relataram as testemunhas-as notificações juntadas aos autos determinaram a imediata suspensão das atividades de empreendimentos em torno dos quais havia, segundo os depoimentos, aglomeração que ocasionava poluição sonora. APELO DO RÉU PROVIDO. APELO DO AUTOR E REEXAME NECESSÁRIO PREJUDICADOS. (Apelação e Reexame Necessário No 70060576063, Vigésima Segunda Câmara Cível, Tribunal de Justiça do RS, Relator: Marilene Bonzanini, Julgado em 06/04/2015).(TJ-RS - REEX: 70060576063 RS, Relator: Marilene Bonzanini, Data de Julgamento: 06/04/2015, Vigésima Segunda Câmara Cível, Data de Publicação: Diário da Justiça do dia 08/04/2015)
\end{abstract}

Diversos doutrinadores e decisões jurisprudenciais negam ao poder judiciário o controle e o compelimento ao Estado na implementação de políticas públicas sob o argumento de suposta violação aos princípios da Separação dos Poderes, da violação da Discricionariedade Administrativa e da Cláusula da Reserva do Possível (PAGLIARINI, 2014, p. 81).

Exemplos:

Ementa: APELAÇÃO CÍVEL. AÇÃO CIVIL PÚBLICA. ANIMAIS ABANDONADOS. POLÍTICAS PÚBLICAS. IMPOSSIBILIDADE DE INTERVENÇÃO. 1. Não cabe ao Poder Judiciário interferir nos atos da administração relativos à política pública de animais abandonados, pois se trata de ato discricionário da administração que, com base na conveniência e oportunidade, tem liberdade de escolher onde as verbas orçamentárias devem ser aplicadas e em quais obras investir, com a finalidade de assegurar o interesse público. Precedentes. 2. Embora não se desconheça da problemática envolvendo animais de rua em situação de abandono, o município demandado não tem se mantido totalmente inerte em frente a esta situação, promovendo campanhas de educação ambiental e de posse responsável de animais de estimação, tendo, inclusive, criado a Lei Municipal $n^{\circ} 845 / 2015$, autorizando a compra de injeções contraceptivas para fêmeas caninas, objetivando o controle dos cães de rua. APELAÇAO IMPROVIDA. (Apelação Cível N ${ }^{\circ}$ 70076746585, Quarta Câmara Cível, Tribunal de Justiça do RS, Relator: Francesco Conti, Julgado em 28/03/2018)

Ementa: APELAÇÃO CÍVEL. DIREITO PÚBLICO NÃO ESPECIFICADO. AÇÃO CIVIL PÚBLICA. ANIMAIS ABANDONADOS EM VIA PÚBLICA. 
SAÚDE AMBIENTAL. POLÍTICAS PÚBLICAS. DESCABIMENTO DE INTERVENÇÃ̃O JUDICIAL. 1. Caso em que a instrução do feito não revelou a total omissão alegada na inicial, uma vez que, conforme comprovam os atos legislativos juntados ao processo, o ente público vem destinando, desde o ano de 2010, verba orçamentária específica para a Associação de Proteção dos Animais de Soledade (APAS), no valor atual aproximado de $\mathrm{R} \$ 2.500,00$ mensais, com o objetivo de realização de trabalho de acolhimento e proteção dos animais de rua. 2. Não deve o Poder Judiciário interferir sobre atos da administração relativos à política de controle de animais em situação de rua, os quais dependem de exame de conveniência e oportunidade que leva em conta as carências e necessidades, assim como disponibilidades orçamentárias do ente municipal como um todo. 3. Sentença de improcedência na origem. APELAÇÃO DESPROVIDA. (Apelação Cível No 70073672636, Quarta Câmara Cível, Tribunal de Justiça do RS, Relator: Eduardo Uhlein, Julgado em 25/10/2017)

Em suma, a diversidade de entendimento jurisprudencial gira em torno da alegação do princípio da reserva do possível, que protege o poder executivo quanto a sua omissão, pelo fato da argumentação de falta de disponibilidade orçamentária; e a violação ao poder discricionário da administração, não devendo atribuir ao poder judiciários certas análises, tratando-se principalmente aos direitos individuais.

\section{CONSIDERAÇÕES FINAIS}

Diante da contextualização apresentada, baseada no referencial teórico e da análise jurisprudencial avençada, pode-se depreender que no Brasil, o direito fundamental ao meio ambiente ecologicamente equilibrado previsto na Constituição Federal de 1988 representa um importante avanço, embora necessite de maiores esforços para alcançar um nível de eficácia social adequado e suficiente.

A formulação e implementação de políticas públicas ambientais além de instrumentos de ação, consideram-se um campo técnico-científico onde a Administração Pública brasileira ainda encontra-se engatinhando e cometendo erros, sobretudo o incorreto balanceamento entre interesses econômicos e ambientais, embora seja o meio aparentemente eivado de esperança de retorno para sociedade no que se refere ao mínimo de direitos a serem concretizados por parte do Estado, apenas necessitando de aprimoramento de técnicas de gestão e de gestores envolvidos com o sucesso.

O Estado tem o dever de formular instrumentos necessários para efetivação da garantia dos direitos fundamentais da sociedade, esses meios devem ser utilizados por intermédio de políticas públicas ambientais, tanto em caráter de política de governo ou política de Estado, conforme demonstrado, e, que possam concretizar o retorno eficaz de caráter socioambiental. 
Para tanto, evidente e necessária a utilização do rigor técnico, para finalidade de gestão, com a observação da consequente avaliação das políticas públicas por ele implementadas.

Todavia, no caso de omissão Estatal no seu papel de direitos e deveres com o meio ambiente, e na observação dos procedimentos que envolvem o ciclo da política pública, pressupõem-se da necessidade de haver nova tentativa de debate, e mecanismos alternativos na resolução de conflitos para evitar que ocorra tão somente a judicialização das políticas públicas. Ademais, como forma de evitar a judicialização sugere-se a criação de debates, audiências públicas da manutenção de contato direto entre sociedade e Estado, tende a propiciar mais efetividade no agir do Estado, evitando assim, a judicialização das políticas públicas socioambientais.

Ainda assim, em não restando alternativa, e pelo entendimento supra do contexto estudado, percebe-se a necessidade do controle pelo poder judiciário no que se refere a concretização das políticas públicas implementadas ou obrigação de implementação destas. Concluindo-se que, em não havendo excesso na interferência entre os poderes administrativos da união, de maneira que sejam respeitados os limites constitucionais previstos, não existe óbice a este controle.

Devem serem observados com cautela e com a ponderação necessária, quanto as negativas judiciais que determinam a não intervenção dentre a competência dos poderes administrativos, levando em consideração o princípio da reserva do possível, criando empecilho protelatório contra o meio ambiente, com o fim de evitar que o meio ambiente arque com consequências e atribuições de falta de implementação de política pública, vinculada pela inércia estatal, mesmo tratando-se de um direito fundamental, sob alegação de falta de recurso orçamentário por parte do Estado, já que, direitos fundamentais são garantias constitucionais que carecem de atenção redobrada das três esferas de poder.

\section{REFERÊNCIAS BIBLIOGRÁFICAS}

- ANDERSON, Perry (1995). Balanço do neoliberalismo. In: SADER, Emir \& GENTILI, Pablo (org). Pósneoliberalismo:as políticas sociais e o Estado democrático. Rio de Janeiro: Paz e Terra. In:paje.fe.usp.br/ mbarbosa/cursograd/anderson.doc

BECK Ulrich, Sociedade de Risco: rumo a uma outra modernidade. Editora 34.2011

BOSCHETTI, Ivanete et al. (Orgs.). Capitalismo em Crise: política social e direitos. São Paulo : Cortez, 2010.

COUTINHO, Diogo. O direito nas políticas públicas. In: MARQUES, Eduardo e FARIA, Carlos Aurélio. A política pública como campo multidisciplinar. São Paulo: Editora Unesp; 
Rio De Janeiro: Editora Fiocruz, 2013. p. 181-200. (pdf)

DAGnINO, Evalina (Org.). Sociedade Civil e Espaços Públicos no Brasil. São Paulo : Paz e Terra, 2002.

DUARTE, Clarice Seixas. Para além da judicialização: a necessidade de uma nova forma de abordagem das políticas públicas. O Direito na Fronteira das Políticas Públicas. Organizadores Gianpaolo Poggio Smanio, Patricia Tuma Martins Bertolin, Patricia Cristina Brasil.-São Paulo: Páginas \& Letras Editora e Gráfica, 2015.

EMERIQUE, Lilian Balmant; FERNANDES, Bárbara de Souza; GANDELMAN, Bernard ; SOUZA, Maíra Sirimaco Neves de. Reflexões sobre o exame jurisdicional de políticas públicas de direitos sociais. In: Âmbito Jurídico, Rio Grande, XV, n. 103, ago 2012. Disponívelem: $<$ http://www.ambitojuridico.com.br/site/index.php/?n_link=revista_artigos_leit ura\&artigo_id=12076\&revista_caderno=9>. Acesso em abr 2018.

PEREIRA, Potyara A. P. Política social: temas \& questões. 2. ed. São Paulo : Cortez, 2009

PAGLIARINI, Alexandre Coutinho, SOUZA, José Washington Nascimento de (organizadores). Direito Econômico e Socioambiental. 1ed.-Rio de Janeiro: LMJ Mundo Jurídico, 2014.

SALHEB, Gleidson.Políticas Públicas e Meio Ambiente: Reflexões Preliminares. Disponível em: <https://periodicos.unifap.br/index.php/planeta/article/view/57> Acesso em 15/04/2017. Planeta Amazônia: Revista internacional de Direito Ambiental e Políticas Públicas (ISSN 2177-1642). Publicação oficial do Programa de Mestrado em DireitoUNIFAP.

SILVA, Christian Luiz da; Souza Lima, Jose Edmilson (orgs.) Políticas Públicas e Indicadores para o Desenvolvimento Sustentável. Sáo paulo saraiva 2010.

TREVISAN, Andrei P. e VAN BELLEN, Hans M. Avaliação de políticas públicas: uma revisão teórica de um campo em construção. RAP - Rio de Janeiro 42(3):529-50, maio/jun. 2008. In: http://www.scielo.br/pdf/rap/v42n3/a05v42n3.pdf

RF-2-AC: 200650030001363 RJ, Relator: Desembargadora Federal NIZETE LOBATO CARMO, Data de Julgamento: 20/10/2014, SEXTA TURMA ESPECIALIZADA, Data de Publicação: 03/11/2014. Jusbrasil, 2014. Disponível em: < https://trf2.jusbrasil.com.br/jurisprudencia/160028851/apelacao-civel-ac-200650030001363-rj/inteiroteor-160028964>. Acesso em 09 março 2018.

TRF-4-AC: 17675 SC 2004.72.00.017675-8, Relator: MARGA INGE BARTH TESSLER, Data de Julgamento: 26/08/2009, QUARTA TURMA).

TRF4, AC 5029531-40.2014.4.04.7200, TERCEIRA TURMA, Relatora VÂNIA HACK DE ALMEIDA, juntado aos autos em 27/02/2018)

TJ-RS-REEX: 70060576063 RS, Relator: Marilene Bonzanini, Data de Julgamento: 06/04/2015, Vigésima Segunda Câmara Cível, Data de Publicação: Diário da Justiça do dia 
08/04/2015)

Apelação Cível No 70076746585, Quarta Câmara Cível, Tribunal de Justiça do RS, Relator: Francesco Conti, Julgado em 28/03/2018.

Apelação Cível No 70073672636, Quarta Câmara Cível, Tribunal de Justiça do RS, Relator: Eduardo Uhlein, Julgado em 25/10/2017. 